\section{EU Emissions Trading in a Crowded National Climate Policy Space - Some findings from the INTERACT project}

\author{
by Jos Sijm, Energy Research Centre of \\ the Netherlands (ECN); and Steve Sorrell, \\ Science and Technology Policy Research \\ (SPRU), University of Sussex
}

Climate policy in EU Member States is becoming increasingly crowded. Multiple instruments have been introduced at both the Member State and EU levels and new instruments are regularly being proposed. As the number of instruments grows, so does the potential for interaction between them. This interaction can be complementary and mutually reinforcing, but there is also the risk that different policy instruments will interfere with one another and undermine the objectives and credibility of each. The central aim of the EU-funded research project "Interaction in EU Climate Policy" (INTERACT) has been to develop a systematic approach to analysing policy interaction and to use this approach to explore the potential interactions between the proposed EU Emissions Trading Scheme (EU ETS) and other instruments within both EU and Member State climate policy. ${ }^{1}$

\section{The INTERACT project}

The INTERACT project was conducted over a two-year period between March 2001 and March 2003. The project was co-ordinated by SPRU (Science and Technology Policy Research) at the University of Sussex (UK), in collaboration with: the Energy Research Centre of the Netherlands (ECN), the Fraunhofer Institute for Systems and Innovation Research (ISI), the Centre International de Recherche sur l'Environnement et le Développement (CIRED), and the Energy Policy Group (EPG) at the National and Kapodistrian University of Athens (NKUA). SPRU was responsible for the overall direction of the project, while each Partner was primarily responsible for empirical research within their own Member State. The Partner institutes in each participating Member State selected a minimum of three national climate policy instruments, examined their potential interactions with the EU ETS and developed a number of policy recommendations. Table 1 summarises the general categories under which the selected instruments fell. Note that there is frequently more than one instrument within each general category. ${ }^{2}$

Table 1: Types of policy instruments examined in each case study

\begin{tabular}{|l|c|c|c|c|c|}
\hline Category & UK & $\begin{array}{l}\text { Nether- } \\
\text { lands }\end{array}$ & $\begin{array}{l}\text { Ger- } \\
\text { many }\end{array}$ & France & Greece \\
\hline $\begin{array}{l}\text { Carbon/energy } \\
\text { taxes }\end{array}$ & $\checkmark$ & $\checkmark$ & $\checkmark$ & & \\
\hline $\begin{array}{l}\text { Negotiated } \\
\text { agreements }\end{array}$ & $\checkmark$ & $\checkmark$ & $\checkmark$ & $\checkmark$ & \\
\hline $\begin{array}{l}\text { Support mecha- } \\
\text { nisms for renew- } \\
\text { able electricity }\end{array}$ & $\checkmark$ & $\checkmark$ & $\checkmark$ & $\checkmark$ & $\checkmark$ \\
\hline $\begin{array}{l}\text { Industrial pollu- } \\
\text { tion control }\end{array}$ & $\checkmark$ & & & $\checkmark$ & $\checkmark$ \\
\hline $\begin{array}{l}\text { GHG emissions } \\
\text { trading }\end{array}$ & $\checkmark$ & & & $\checkmark$ & \\
\hline $\begin{array}{l}\text { Promotion of } \\
\text { energy efficiency }\end{array}$ & $\checkmark$ & & & & \\
\hline
\end{tabular}

\section{Implications of the EU ETS for Policy} Interaction

A defining feature of a "cap and trade" emissions trading scheme - such as the EU ETS - is that, assuming adequate enforcement and full compliance, there is certainty that total emissions will be equal to the aggregate cap. ${ }^{3}$ A second feature of a cap and trade scheme is that, under a standard set of assumptions regarding the competitive operation of the allowance market, the trading scheme will allow the target to be met at least cost. In the equilibrium, marginal abatement costs will be equalised across sources and equal to the allowance price.

These idealised features of an ETS have important implications for policy interaction. Coupled with comparable assumptions regarding the idealised operation of the relevant product markets, they imply that the use of a second instrument that directly or indirectly interacts with the ETS will increase the overall costs of meeting the emissions cap while at the same time having no influence on environmental effectiveness - where the latter is defined as assurance in meeting the ETS cap. The aggregate abatement costs of ETS participants may be either increased (e.g. by a carbon tax) or reduced (e.g. by a subsidy scheme) by the 
second instrument, but in all cases the aggregate social costs of meeting the cap will be increased and participant emissions will continue to be less than or equal to the cap. This result applies both to instruments which directly affect $\mathrm{CO}_{2}$ emissions from ETS participants, such as a carbon tax on fuel use, and to instruments which indirectly affect those emissions, such as a tax on electricity consumption of both participants and non-participants.

In practice, allowance and product markets may only approximate the theoretical ideal. Market failures will be pervasive in both markets and the political bargaining that led to the ETS cap is unlikely to provide an adequate reflection of the "social optimum" for carbon externalities (to the extent that such a concept is meaningful for global climate change). In addition, governments have objectives which go beyond efficiency, such as the promotion of social equity. In these circumstances, there may be legitimate grounds for introducing or maintaining other climate policy instruments that directly or indirectly interact with the ETS. These include:

- improving the static efficiency of the ETS by overcoming market failures other than $\mathrm{CO}_{2}$ externalities that inhibit the adoption of energy efficiency technologies;

- improving the dynamic efficiency of the ETS by overcoming market failures in the area of technology innovation and diffusion;

- delivering social objectives other than efficiency, such as equity and political feasibility; and

- compensating for deficiencies in the ETS design such as mitigating allowance price uncertainty.

However, the fact that positive combinations between an ETS and other instruments are theoretically possible does not mean that such combinations will result when an ETS is introduced into an existing policy mix. Furthermore, when an ETS is in place, aggregate emission reductions will be set solely by the ETS cap. Instruments which target emissions covered by the ETS cap will contribute nothing further to emission reductions - unless they are sufficiently stringent that they make the ETS redundant. This means that, once the ETS is in place, the justification for maintaining such instruments must rely upon one of the above rationales, rather than the contribution of the instrument to overall emission reductions.

In the following, an example of the possible interaction between the EU ETS and voluntary or "negotiated agreements" (cf. Table 1) in the Netherlands is outlined.

\section{Case study: the interaction between the EU ETS and the Benchmarking Covenant in the Netherlands}

The Benchmarking Covenant (BC) is a voluntary agreement, signed in July 1999 by the Dutch government and energy-intensive industry, including the electricity production sector. The central goal of the Benchmarking Covenant is to reduce GHG emissions from energyintensive industries by improving their energy efficiency without compromising the international competitiveness of these industries. According to the $\mathrm{BC}$, participating industries are required to become close to the world best practice in terms of energy efficiency as soon as possible, but no later than 2012. The interaction between the EU ETS and the $\mathrm{BC}$ raises a variety of issues, including:

- The impact of the EU ETS on electricity prices. The EU ETS may have a significant impact on the price of electricity, which, in turn, may have a significant, although opposing impact on the two major sectors covered by the Benchmarking Covenant, i.e. the power producers versus energy-intensive industries. Emissions trading at an allowance price of $€ 10 / \mathrm{tCO}_{2}$ may lead to an increase of the electricity price in 2010 by $0.42 € c e n t / k W h$. Based on a commodity or producer cost price of $2.7 €$ cent $/ \mathrm{kWh}$ before emissions trading, this implies an increase of that price of some 15 percent due to the EU ETS. If the EU ETS will indeed result in an increase in average electricity prices of $0.42 €$ cent $/ \mathrm{kWh}$, it will have a significant impact on the two major sectors covered by the Benchmarking Covenant. In case of free allocation of allowances, more than $€ 400$ million of economic rent will accrue to the power sector, while energy intensive industries that compete on global markets will not be able to pass on increases in electricity prices to their customers. As a result, the 
output of these industries may decline when the electricity price is raised.

- The Benchmarking Covenant as a basis for allocating EU ETS allowances. A major interaction issue concerns the question of whether the BC could be used as a basis for allocating EU ETS allowances. The advantages of such an approach are that it fits well with the existing climate policies in the Netherlands, it would meet several of the allocation criteria specified in Annex III of the EU ETS Directive, and that it increases the political acceptability of the EU ETS among the participants of the $\mathrm{BC}$. However, allocation of allowances based on the Benchmarking Covenant is likely to imply that the socio-economic benefits of emissions trading in the Netherlands will be relatively low. Moreover, the conversion of energy efficiency benchmarks into $\mathrm{CO}_{2}$ emission quotas raises a variety of practical implementation issues which may lead to high information and transaction costs. Overall, in a multi-criteria assessment, the coexistence of the EU ETS and the BC, notably when the allocation of the emission allowances is based on the $\mathrm{BC}$, scores relatively high in terms of industrial competitiveness and political acceptability, but relatively low in terms of economic efficiency and administrative simplicity.

\section{Policy recommendations}

The INTERACT project has made a number of specific policy recommendations for each of the participating Member States. These recommendations vary according to the specific circumstances of the Member State and the interpretations given by each of the research teams. But the following general principles of climate policy development may be highlighted:

- Goals: The development of policy options should be based upon clear principles and long-term goals. For climate policy, a stable and effective policy framework is required during the Kyoto commitment period. This means that policy should be developed by working back from where we want to be in 2008 , rather than developing short-term expedients.
- Carbon pricing: Energy users in all sectors should pay for carbon emissions, whether through taxation or emissions trading. In the long term, organisations in the public, commercial and industrial sectors should either be paying a carbon tax or participating in a trading scheme. Supplementary policies will be required to address other barriers to energy efficiency and to achieve other policy objectives, such as promoting renewables. But for each target group, only a single instrument should be used for carbon pricing.

- Electricity: The direct approach to electricity emissions used in the EU ETS is preferable to the indirect approach used in a number of national climate policies because: first, it gives compliance obligations for electricity emissions to the companies directly responsible for the control of those emissions, thereby incentivising both fuel switching and energy efficiency; and second, it facilitates cross-border electricity trade in the EU.

- Targets: Absolute targets are to be preferred over relative targets because of their greater environmental integrity and consistency with the national emission targets under Kyoto. And allowance based trading is to be preferred over baseline and credit trading due to its greater economic efficiency, lower transaction costs and consistency with the Kyoto framework. The EU ETS reflects these considerations while many of the existing policies at the Member State level do not. The latter should therefore be considered as transitional measures only.

- Supplementarity: There is a risk that abatement in the EU ETS will be achieved through purchasing cheap "hot air" from outside the scheme, rather than through domestic action. But domestic abatement may be incentivised by either restricting the interface between the EU ETS and the international carbon market, or by retaining (or establishing) "backup" regulations for EU ETS participants. The first approach is preferable, but is dependent upon the final outcome of the proposed "linking" directive. In general, "backup" regulations should be avoided as they are likely to undermine economic efficiency, be more complex to administer and lead to additional costs for the target groups. 
There is scope for debate over these principles and over the specific recommendations given in each of the case study reports. But the main point is to encourage wider recognition of the challenges and opportunities that the EU ETS creates.

\section{Notes}

1) The proposed EU Emissions Trading Scheme (EU ETS) is expected to cover some $45 \%$ of EU $\mathrm{CO}_{2}$ emissions from 2005 onwards. Participants include electricity generators, oil refineries and energy intensive manufacturing installations in sectors such as iron and steel, minerals and paper. Phase 1 of the EU ETS runs from 2005 to 2008, and Phase 2 from 2008 to 2012. As the EU ETS expands over time to cover more sectors and greenhouse gases (GHGs), the scheme will cover an increasingly large proportion of the total EU emissions regulated under the UNFCCC/Kyoto Protocol.

2) Further information on the INTERACT project, including a list of downloadable reports and policy briefs, is available on the web site: http://www.sussex.ac.uk/spru/environment/resea $\mathrm{rch} /$ interact.html.

3) In a cap and trade emissions trading scheme for $\mathrm{CO}_{2}$ emissions, a fixed number of emission allowances are allocated each year to the participating sources. Each participant must surrender one allowance for every tonne of $\mathrm{CO}_{2}$ emitted. Participants who face high abatement costs can continue to emit by buying additional allowances, while participants who face low abatement costs can take abatement action and sell their surplus allowances for a profit. In this way, each participant can minimise its overall abatement costs. The scheme places an overall "cap" on the annual quantity of $\mathrm{CO}_{2}$ emissions equal to the number of allowances distributed, and the trading mechanism should allow this cap to be achieved at the lowest possible cost.

\section{Contact}

Jos Sijm

Energy Research Centre of the Netherlands (ECN)

Badhuisweg 3, NL 1031 CM Amsterdam

The Netherlands

Tel: +31 - 224568255

Fax: + 31 - 204922812

E-Mail: sijm@ecn.nl

Internet: http://ww.ecn.nl/ 